\title{
REFORMA EDUCATIVA Y LUCHAS DOCENTES EN AMÉRICA LATINA*
}

\author{
Pablo Gentili* \\ Daniel SuÁrez \\ FLORENCIA STUBRIN \\ JuLIÁN Gindín
}

\begin{abstract}
RESUMEN: El presente artículo propone algunos ejes para el análisis de la conflictividad educativa en el marco más amplio de la intensificación de los procesos de conflictividad social y política que tuvieron y tienen lugar en los países de América Latina durante las últimas dos décadas. Buscando contribuir a una comprensión crítica de la conflictividad docente, los autores presentan algunos datos cuantitativos que permiten establecer tendencias generales respecto de las características y dinámicas adoptadas por las acciones de protesta impulsadas por las organizaciones magisteriales en 18 países de la región. Asimismo, intenta enriquecer e incentivar el debate en torno a la conflictividad educativa, procurando una definición y conceptualización del conflicto educativo y docente que, a partir de una reflexión acerca de las políticas y programas de reforma neoliberales, ofrezca elementos para el desarrollo de análisis alternativos sobre la problemática docente, así como para la construcción de propuestas y alternativas democráticas de cambio de los sistemas educativos latinoamericanos.
\end{abstract}

Palabras claves: Sindicalismo docente. Reformas educativas. Conflicto educativo. Conflicto social. Neoliberalismo. Lutas docentes. América Latina.

\footnotetext{
* Este artículo constituye una versión resumida de uno de los capítulos del libro Reforma educacional e luta democrática. Um debate sobre a ação sindical docente na América Latina, organizado por Pablo Gentili y Daniel Suárez (São Paulo: Cortez, 2004). Tuvo su origen en una investigación promovida por OREALC/UNESCO (Chile) y coordinada por el Laboratorio de Políticas Públicas (Sede Buenos Aires). Las opiniones aquí vertidas no representan, necesariamente, las de la UNESCO.

** Pesquisadores do Laboratorio de Políticas Públicas (Rio de Janeiro/Buenos Aires), Observatorio Latinoamericano de Políticas Educativas (OLPED/LPP). E-mails: pablo@lpp-uerj.net/ daniel@lpp-buenosaires.net/florência@lpp-buenosaires.net/julian@lpp-uerj.net.
} 


\title{
EDUCATIONAL REFORM \\ AND TEACHER'S STRUGGLES IN LATIN AMERICA
}

\begin{abstract}
This article suggests some axes for the analysis of the learning activity, in the wider scope, of the intensification of processes of social and political conflicts that happened and, even today, in Latin American countries, during the last two decades, Attempting to contribute to a critic comprehension of the teachers' conflict, the author hereby bring some quantitative data that allow the establishment of general tendencies regarding the characteristics and dynamics adapted by actions of protest augmented by the teaching organization in eighteen countries of that region. Yet trying to enrich and encourage the debate about teachers' conflict of education, searching for an educational conflict definition and conceptualization, springing from a reflex ion with respect to politics and neoliberal reformation programs, may offer elements for the development of alternative analysis on teacher's difficulties, as well as for the building of proposals and democratic alternatives for the change of Latin American systems of education.
\end{abstract}

Key words: Teachers association. Educational reform. Educational conflict. Social conflict. Neoliberalism. Teacher's struggle. Latin America

\section{La reforma educativa como escenario de conflicto}

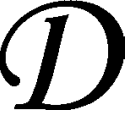

urante los últimos 20 años, los países de América Latina han asistido a una ampliación, diversificación e intensificación de la conflictividad social y política. ${ }^{1}$ Más allá de la irrupción de nuevos sujetos en confrontación y la multiplicación de los escenarios de conflicto, la mayor parte de los enfrentamientos tuvieron como protagonista principal al sector asalariado (público y privado) sindicalizado y, en particular, al sector docente (maestros y profesores). ${ }^{2} \mathrm{Si}$ a esa constatación agregamos el hecho de que los estudiantes universitarios - y, en algunos casos, las comunidades universitarias en su conjunto - también han realizado numerosas acciones de protesta y de movilización reivindicativa, resulta fácil advertir la centralidad que ha venido asumiendo el conflicto del campo educativo en el terreno de la conflictividad social latinoamericana.

Nucleados a través de sindicatos y organizaciones y movimientos sociales docentes, estudiantes y otros actores sociales y educativos, vienen litigando hace años con el Estado, sus funcionarios políticos y cua- 
dros técnico-administrativos. Ya sea en la lucha de barricada o en la arena de la negociación, ya sea a través de modalidades tradicionales o mediante nuevas formas de protesta, han venido disputando espacios, recursos, símbolos y beneficios públicos y privados con los planteles estatales. En casi todos los países de la región, además, esas luchas y negociaciones tuvieron como escenario sociedades y economías en crisis y, en ese contexto, sistemas educativos debilitados, organizados central y burocráticamente, desfinanciados y segmentados internamente. También, procesos de reformas educativas integrales y fundantes que, bajo el lema de "la calidad, la equidad y la eficiencia" y una importante movilización de recursos y estamentos públicos, pretendieron modificar de raíz la estructura del sistema escolar, el currículum de todos los niveles y modalidades educativas, la organización y la gestión de los sistemas y de los establecimientos educativos, la cultura organizacional y las tradiciones de estas instituciones.

Resulta evidente que la mayor parte de los conflictos que tuvieron y tienen lugar en el campo educativo latinoamericano han girado en torno a cuestiones específicas del campo docente, a través de un conjunto de reivindicaciones históricas del sector. Estos conflictos docentes parecen poner en tensión las pretensiones de cambio de las administraciones políticas de la educación, con la constatación de una serie de situaciones en las que parece desdibujarse la propia capacidad de éstas para garantizar las condiciones básicas de la escolaridad. Dicho de otra manera: en América Latina, el aumento de la conflictividad docente parece estar mostrando la distancia existente entre los ambiciosos programas de reforma educativa implementados en los países de la región durante la década del ' 90 y la fragilidad o precariedad de las condiciones políticas, económico-financieras y normativas sobre las cuales descansa la misma reproducción de los procesos de escolarización, al menos tal cómo se habían venido perfilando durante el último siglo.

Una rápida lectura de los reportes y crónicas periodísticas especializadas permite apreciar que los temas en disputa más importantes entre sindicatos docentes y Estado se relacionan casi exclusivamente con las condiciones salariales y laborales de maestros y profesores, el presupuesto para la educación, la falta o precariedad de incentivos y estímulos económicos para el sector, los estatutos docentes (convenios colectivos de trabajo del sector) y normas que regulan el trabajo en las instituciones educativas $y$, en última instancia, la capacitación y el perfeccionamiento 
profesional. ${ }^{3}$ Por otra parte, es fácil constatar, en esta agenda, una peligrosa reducción de la problemática docente a cuestiones importantes, pero parciales, desarticuladas entre sí y con efectos a corto plazo. La ausencia de una mirada global y holística, que tienda a problematizar y articular las diversas dimensiones involucradas con la organización y gestión del trabajo de enseñar en instituciones educativas en una política docente integral, parecería estar limitando tanto la concepción, gestión y evaluación de las políticas educativas que impulsan los gobiernos como las respuestas y reivindicaciones que el sector docente antepone para su desarrollo y/o implementación.

Quizás por efecto de la ausencia de ese marco referencial más complejo y estratégico que contribuya a llevar la mirada, la comprensión y la intervención hacia el mediano y largo plazo, resulta evidente también un cierto carácter cíclico en la evolución y desenlace de los conflictos educativos en los países de la región: en un primer momento, la confrontación a través de huelgas y movilizaciones motorizadas por el sector docente y sus sindicatos contra el Estado; luego, una ronda de negociaciones puntuales entre los referentes políticos y funcionarios de los gobiernos (fundamentalmente de las carteras educativas, pero cada vez más intensamente de los equipos económicos) y los representantes gremiales; inmediatamente, una serie de acuerdos y temas concertados entre las partes en conflicto, generalmente precarios y de corto plazo; en la mayoría de los casos, un período de relativa estabilidad, no exento de amenazas, sospechas y conflictos menores; finalmente y casi de manera inexorable, una nueva ronda de confrontaciones y conflictos que emergen como una evidencia más de las condiciones que impiden estructurar y llevar a la práctica criterios democráticos y participativos para la gobernabilidad educativa y el funcionamiento adecuado de la educación pública.

Sin embargo, más allá de estas especificidades, el peso relativo de la conflictividad educativa en los países de la región no es ajeno a otra serie de procesos asociados con la profundización de la crisis económica (recesión, desocupación, pobreza, desinversión pública etc.) y la inestabilidad política de los gobiernos; la redefinición de las condiciones internacionales y locales para el desarrollo y crecimiento sustentable de las economías y sociedades latinoamericanas; y los procesos de creciente pauperización, desigualdad y exclusión social que las aquejan. Directa o indirectamente, algunas interpretaciones atribuyen las causas de esta situación y estas tensiones a los efectos perniciosos de los procesos de 
"globalización neoliberal”; ${ }^{4}$ a las políticas de "ajuste estructural” y/o de control/reducción del gasto público implementadas por los gobiernos; ${ }^{5}$ a la redefinición del rol del Estado como garantía de los derechos sociales (entre ellos, el derecho a una educación de calidad para todos); y a los procesos de privatización y mercantilización de la educación. ${ }^{6} \mathrm{De}$ acuerdo con estos análisis, la desestabilización de la "sociedad salarial" y la desarticulación del Estado Bienestar Social (o de sus rudimentos), en América Latina, han provocado el colapso del tradicional sistema de cooperación e inclusión social, que tendía a organizar el campo educativo a partir de una particular asignación de recursos, patrones de distribución y modalidades de concertación y/o reivindicación actualmente en crisis. En este marco, resulta difícil identificar los límites y posibilidades de confrontación de los actores, sus potenciales aliados y adversarios, los espacios en los que se definen nuevos consensos, con independencia del profundo proceso de transformaciones vividas por las sociedades latinoamericanas contemporáneas.

Otros enfoques, más focalizados en el estudio de las reformas educativas impulsadas por los gobiernos de los países de la región y sus impactos sobre las condiciones (materiales y simbólicas) de trabajo del sector docente y los procesos de sindicalización docente, tienden a vincular los conflictos educativos con la emergencia y multiplicación de reivindicaciones sectoriales y colectivas. Según esos estudios, muchas de las demandas tienen como eje la defensa y/o ampliación de los derechos laborales y sindicales de los trabajadores de la educación y, como telón de fondo, discursos a favor de la defensa del derecho social a la educación. Desde estas perspectivas, las reformas educativas implementadas portan y desarrollan un conjunto de valores y modelos organizacionales y de gestión que son considerados por los sindicatos y los docentes como ajenos a las concepciones y modalidades en torno a las cuales construyeron sus identidades y fundamentaron su acción colectiva.

Un grupo importante de investigaciones complementa esta mirada al plantear que la significativa movilización de recursos y estamentos públicos implicados en los procesos de reforma educativa de los países latinoamericanos, durante los años ' 90 , han configurado nuevas regulaciones sobre la organización del trabajo y la carrera profesional de los docentes, las cuales han sido visualizadas por el sector, y sobre todo por sus entidades sindicales, como una amenaza a las conquistas y reivindicaciones alcanzadas durante los años inmediatamente anteriores. ${ }^{7}$ Entre esas 
"transformaciones amenazantes" impulsadas por las reformas es posible identificar:

a) Las tentativas de modificación de las carreras profesionales de los docentes, a través de cambios en las normativas y estatutos que regulan el tránsito por el escalafón laboral.

b) Los cambios impulsados en la estructura salarial del sector.

c) La incorporación diferencial de incentivos por desempeño como parte del salario real de los docentes. ${ }^{8}$

d) Las políticas de descentralización de la administración y gestión de las instituciones educativas, en tanto redefinen y desconcentran la arena de negociación entre sindicatos docentes y Estado.?

e) Las políticas curriculares, de formación y perfeccionamiento docente y de evaluación del desempeño docente, en tanto modalidades de implementación top-down de las reformas que tienden a proletarizarlos, desautorizar sus experiencias, prácticas convencionales y saberes profesionales, y recualificarlos como ejecutores de pautas y prescripciones "expertas", externas y ajenas a la cultura escolar. ${ }^{10}$

Desde un punto de vista diferente a los anteriores, otros estudios han identificado como un importante "obstáculo político" para la implementación de las reformas educativas, justamente, a la conflictiva relación que sostienen los sindicatos docentes y los representantes gubernamentales promotores de los cambios en el sector. Sobre todo, porque atribuyen poca influencia y poder a los funcionarios de alto rango (ministros, secretarios y otros funcionarios políticos), en virtud de su escasa permanencia en los cargos que ocupan, y una incidencia relativamente mayor a los sindicatos y otros actores sociales demandantes (las familias, las corporaciones etc.). Estos enfoques focalizan la atención sobre cuestiones relativas a la gobernabilidad y eficiencia de los sistemas educativos y los procesos de reforma e innovación sistémica de la educación, advirtiendo acerca de la necesidad de generar condiciones políticas y técnicas adecuadas para garantizar cierta estabilidad y continuidad de las políticas educativas, así como un marco de consenso mínimo que permita diseñar y llevar a la práctica una estrategia de concertación a mediano plazo entre los sectores en litigio. Si bien generalmente no se ocupan en profundidad de los condicionantes históricos y contextuales de la conflictividad educativa, ni 
del sentido y posibles consecuencias de las políticas oficiales de reforma y/ o mejora sobre el trabajo de los docentes, esos estudios señalan las escasas posibilidades de éxito de cualquier política pública o innovación en el campo educativo que no tome en cuenta e intente resolver de manera estructural las tensiones y conflictos que minan la viabilidad política de los emprendimientos estatales. ${ }^{11}$

Lo cierto es que, con la contribución adicional de los formadores de opinión y los medios de comunicación masiva, el campo educativo latinoamericano fue constituyéndose progresivamente y de manera cada vez más evidente en una arena de conflictos, demandas encontradas y reivindicaciones que han provocado decisivas tensiones, marchas y contramarchas en el desarrollo democrático de la vida política, social y cultural de las sociedades y países de la región. A su vez, la agenda pública de conflictos educativos, tal como se ha venido definiendo en los últimos años, está siendo atravesada por las urgencias de los tiempos de crisis, así como por las miradas muchas veces restringidas y cortoplacistas de los sectores en disputa, que impiden un adecuado tratamiento de las condiciones globales, estructurales, que configuran el foco de la problemática y que permitirían el despliegue de soluciones concertadas de mediano y largo aliento. La ausencia de una plataforma conceptual y normativa que promueva la definición y el desarrollo democrático de políticas docentes integrales, así como los obstáculos puestos a la posibilidad de una participación efectiva de todos los actores educativos en el debate y la práctica de una reforma que fortalezca la escuela pública y universalice el derecho a la educación, son tal vez un rasgo común y crítico en todos los países de la región.

\section{Conflicto educativo: hacia una definición teóricamente ambiciosa}

La forma de conceptualizar el conflicto educativo, o en otros términos, la definición de conflicto escogida para analizar esta problemática y su dinámica, determinará especificidades y modos de abordaje diversos dando cuenta de diferentes maneras de pensar la problemática específica del conflicto docente en América Latina.

Considerando a los espacios sociales atravesados por relaciones de poder y de fuerza en los cuales los agentes, en función de su posición relativa, luchan y negocian con otros grupos por definir los límites del campo, se puede pensar el conflicto educativo desde una perspectiva dinámica y compleja. ${ }^{12}$ Es decir, como un proceso constitutivo en el que los agentes o actores 
luchan para imponer o lograr consenso social y político respecto de su propia visión de la educación. Esa visión del conflicto, como un proceso constitutivo de la interacción social en el que la definición de los problemas y prioridades así como las diferentes estrategias utilizadas para imponerlos al resto de los agentes, nos permite recuperar la noción de intereses contrapuestos y el poder relativo con que cada actor cuenta para imponer "su" consenso al resto o para arribar a acuerdos. En este sentido, el conflicto es pensado en forma dinámica; o sea, como un campo de producción y lucha simbólica activo y no meramente reactivo. La conflictividad social no es, por lo tanto, una reacción mecánica de los grupos subalternos a la dominación que ejercen los poderosos. Su estudio, implica reconstruir las prácticas de significación de los sujetos protagonistas para dar cuenta de ese campo de lucha simbólica. De tal forma, esta definición nos permite considerar la posibilidad de interacción de múltiples sujetos en el marco de la conflictividad docente.

En esta misma línea de razonamiento, podemos pensar al conflicto educativo en tanto un elemento consustancial de los procesos sociales donde se evidencian y transparentan los diversos y contradictorios intereses económicos y políticos, los puntos de vista y las percepciones culturales y psicosociales de los actores individuales y colectivos puestos en juego. De ese modo, los conflictos no tienen una única causa sino que aparecen como fenómenos multicausales, resultando necesario comprender la red de sentidos que construye y reconstruye el contexto económico, político y social del país, así como el marco histórico en el que éstos se insertan, para tratar de recuperar los factores que le dieron origen y especificidad histórica a esta problemática.

Desde otra perspectiva, complementaria a la anterior, podríamos considerar al conflicto educativo a partir del entrecruce de procesos de individuación y socialización de sujetos individuales y/o colectivos, históricamente determinados. El conflicto existe donde hay sujetos - con autoconciencia - que buscan construirse como tales, a partir de las diferencias y coincidencias que cada cual tiene con otros. En este sentido, la construcción del yo-magisterial (en sus condiciones de trabajo), como grupo, no debe verse aislada al otro (constituido por estudiantes, padres de familia y sociedad en general). La construcción de la identidad magisterial no siempre coincide con la percepción de los grupos de poder en los gobiernos de turno. El conflicto docente nace de la interacción del magisterio con otros grupos y no respondiendo de forma unilateral y exclusiva a sus intereses. 
Otra manera de conceptualizar el conflicto social se inclina a entender que éste no existe sin la presencia de sujetos organizados, suponiendo al magisterio como grupo social y al gobierno como la expresión de grupos sociales en el poder. Esta definición nos conduce a considerar la construcción histórica de los grupos sociales y a la diferenciación entre sujetos $\mathrm{y}$ actores sociales.

Desde un enfoque socio-organizacional, a su vez, podríamos suponer al conflicto social y educativo como inherente a los sistemas capitalistas. En este sentido, el conflicto entre capital y trabajo, propio de las sociedades capitalistas, no se daría sólo en la esfera privada, sino que también se podría hacer presente en el sector público debido a que las formas de empleo y relaciones de trabajo se procesan a través de formas típicamente capitalistas. De ese modo, el conflicto y la resistencia de los trabajadores tienen lugar en el marco de la organización capitalista del trabajo. De ahí que estos conceptos - conflicto y resistencia - no son neutros, sino que reflejan relaciones sociales históricamente determinadas.

Desde esta perspectiva, los conflictos resultan omnipresentes en la vida social y asumen formas variadas que pueden distinguirse según su naturaleza y objetivos. Ello hace necesario indagar sobre el origen de los conflictos y las manifestaciones que éstos asumen a partir de su contextualización. Podría pensarse, entonces, que el conflicto docente tiene una particularidad que deviene de la especificidad del trabajo docente, es decir, su autonomía.

Finalmente, no hay posibilidad de formular una teoría del conflicto educativo que no parta del análisis, sistematización e interpretación de los conflictos realmente existentes. Por eso, algunas de las teorías disponibles son limitadas, ya que no consideran al magisterio como sujeto social que participa, crea y es parte constitutiva de una dimensión específica del conflicto social (el conflicto educativo).

Nuestra noción de conflicto educativo, como toda noción dialéctica del conflicto social, se sustenta en el carácter procesual y dialéctico de la conflictividad política. Es decir, pretende dar cuenta de los procesos que constituyen y dan sentido a la conflictividad. El conflicto educativo debe ser comprendido en el marco más amplio del conflicto social (sus conexiones, redes y nexos con otras esferas de conflictividad). Dentro de ellas: los procesos de reconversión laboral y sindical, el deterioro de las condiciones de vida de los sectores populares y las diferentes formas de lucha (no siem- 
pre convencionales) que los movimientos sociales desarrollan para resistir a ese deterioro, las disputas inter-sindicales, las estrategias de construcción política que definen las dirigencias sindicales y políticas en cada país.

Por otra parte, un análisis de los conflictos no puede resumirse a la ponderación de los impactos o eficacia que estos tienen para obtener las demandas y conquistas esperadas por quienes movilizan determinadas estrategias de lucha. Desde una perspectiva funcionalista, el conflicto es un medio para obtener ciertos resultados. Aunque ésta constituye, sin lugar a dudas, una de las motivaciones centrales de quienes organizan y motorizan diversas formas de resistencia, un análisis crítico acerca de la conflictividad social debe tratar de esclarecer los factores que, históricamente, permiten comprender la emergencia de ciertas luchas tanto retrospectiva como prospectivamente. Esta cuestión resulta fundamental ya que el débil resultado (en términos de sus demandas formales y explícitas) de algunas de las más importantes movilizaciones docentes promovidas en diferentes países de América Latina, así como su eventual éxito, no siempre explican la emergencia y persistencia de la conflictividad educativa en la región. Las causas de cualquier conflicto social son siempre múltiples, nunca lineales y, menos todavía, subordinadas a una ecuación costo-beneficio de cuyo resultado depende su continuidad o clausura.

Los resultados de la cronología de la acción sindical docente, que presentaremos a continuación, lejos están de ofrecernos un panorama completo y detallado de las razones que crearon y multiplicaron los escenarios de tan intensa conflictividad en el marco de las recientes reformas educativas latinoamericanas. Sin embargo, pueden ayudarnos a ensayar hipótesis y delinear tendencias que contribuyan a comprender mejor una problemática que se lamenta mucho y se estudia poco.

Una cronología de la acción sindical docente en América Latina (1998-2003)

Intentando construir una visión de conjunto de la intensa conflictividad que acompañó los procesos de reforma educativa implementados en América Latina durante la última década, nos proponemos presentar algunas de las informaciones básicas obtenidas a partir de un estudio cronológico acerca de las acciones reivindicativas del magisterio, 
llevadas a cabo por entidades sindicales del sector educativo entre 1998 y $2003 .{ }^{13}$ Dicho estudio tuvo como objetivo principal mapear y compilar las principales estrategias de protesta docente llevadas a cabo en 18 países de América Latina. ${ }^{14}$

Como ya mencionamos, cualquier análisis que aborde las condiciones del cambio educativo en América Latina difícilmente escape al reconocimiento de que los procesos de reforma han sido y son escenario de una alta conflictividad, que tuvo y tiene como uno de sus actores más significativos a las organizaciones magisteriales. Independientemente del juicio de valor que pueda hacerse acerca de esas reformas, lo que parece ser un dato ineludible es que las mismas fueron, para bien o para mal, campo de confrontación y disputa de intereses que, en algunos casos, se tradujeron en momentos de protesta y acciones reivindicativas de larga duración y de una no menos intensa acción represiva, criminalizadora o punitoria por parte de los gobiernos nacionales en casi todos los países del subcontinente. A nadie se le escapa que, más allá de la voluntariosa disposición concertadora que han manifestado los promotores de las reformas, el conflicto ha sido la marca indeleble que acompañó los cambios experimentados por los sistemas educativos latinoamericanos durante las dos décadas pasadas. Tampoco deja de ser evidente que, en su papel de víctimas o victimarios, los sindicatos docentes jugaron un papel central en este conflicto.

Sin embargo, y más allá de estas cuestiones de reconocimiento común, pocos son los estudios que tratan de comprender las causas de esta alta conflictividad y, sorprendentemente, menos los que tratan de ponderar sus tendencias a partir de datos precisos y no apenas aproximativos. ${ }^{15}$ La mayoría de los estudios e investigaciones sobre el tema son escasos y focalizados en casos nacionales. Por su parte, la información sindical suele ser producida a la luz de los conflictos y luchas que las diferentes organizaciones protagonizan.

Ciertamente, resulta difícil analizar cualquier proceso de conflictividad social proclamando objetividad y distanciamiento. De cualquier manera, e independientemente de nuestras simpatías hacia todo movimiento de resistencia y lucha por un mundo mejor, lo que pretendemos aquí es, de forma un tanto esquemática, presentar algunas tendencias respecto de lo que ha ocurrido en materia de acción sindical docente en 18 países latinoamericanos durante los últimos 5 años. Para hacerlo, partiremos de la 
sistematización de datos que consideramos imprescindibles y que fueron relevados de diversas fuentes primarias y secundarias (medios periodísticos, prensa sindical, estudios e investigaciones, entrevistas etc.).

\section{Los resultados obtenidos: algunas tendencias}

La cronología de la acción sindical, realizada en la primera parte de este proyecto, contempla 863 conflictos educativos que tienen como actor central organizaciones gremiales del magisterio. El período analizado corresponde a los 5 años que transcurren entre el 1 de enero de 1998 y el 31 de diciembre de 2003. ${ }^{16}$

Del total de conflictos relevados, 342 (40\%) fueron protagonizados por sindicatos de base; 107 (12\%) por frentes sindicales docentes (entidades de base agrupadas, aunque no perteneciendo a la misma federación); 66 (8\%) por colectivos docentes sin pertenencia sindical definida; 77 (9\%) por la comunidad educativa (incluyendo eventualmente en ésta a ciertas organizaciones magisteriales); 80 (9\%) por federaciones o confederaciones docentes; $70(8 \%)$ por centrales sindicales (con participación de sindicatos magisteriales); 61 (7\%) por frentes sociales (en los que también participan entidades sindicales docentes); y $63(7 \%)$ por otros tipos de organización.

Los principales antagonistas de los conflictos han sido los gobiernos nacionales. Poco más de la mitad de los conflictos relevados (487 $54 \%$ ) fueron motivados por reclamos y demandas a los ministerios de Educación y, especialmente, en los países con un sistema educativo descentralizado, contra gobiernos provinciales o estatales $(274-31 \%)$. Algunos pocos conflictos fueron dirigidos contra administraciones municipales $(46-5 \%)$ o contra administraciones universitarias $(35-4 \%)$. Otros $(52-6 \%)$ tuvieron como escenario confrontaciones entre las propias entidades sindicales del sector o entre tendencias de una misma organización magisterial (es el caso, específicamente, de México).

Llama la atención la ausencia de conflictos que tienen como antagonista al sector privado. Del total de acciones de protesta registradas en nuestra cronología, ninguno ha sido exclusivamente contra las corporaciones privadas de enseñanza. Varias razones podrían explicar este hecho. Por un lado, los sindicatos docentes del sector privado suelen ser, en algunos países, menos organizados y combativos que los del sector público. En algunos casos, 
inclusive, no hay siquiera representación gremial en las organizaciones de trabajadores del magisterio que actúan en la enseñanza privada. Por otro lado, cuando esas organizaciones son más activas y orgánicas, ellas actúan en las federaciones o confederaciones docentes que tienen como sector hegemónico a las entidades del sector público. Asimismo, algunos conflictos en el sector privado suelen ser muy focalizados y circunscriptos a una institución o red de instituciones (por lo cual no siempre ganan notoriedad pública y suelen ser difíciles de registrar en una cronología como la realizada). Finalmente, en la medida en que las remuneraciones docentes y los sistemas de carrera magisterial son, también de manera general, regulados por los gobiernos centrales, buena parte de las demandas de docentes del sector privado son dirigidas contra los ministerios de Educación o, en algunos casos, contra las secretarías provinciales o estatales. De tal forma podríamos establecer que la ausencia de conflictos contra organizaciones corporativas del sector no indican falta de conflictos en el subsistema privado, sino una particular configuración de la conflictividad educativa en países con una gran centralidad del Estado en la provisión de los servicios escolares y en la regulación del trabajo docente.

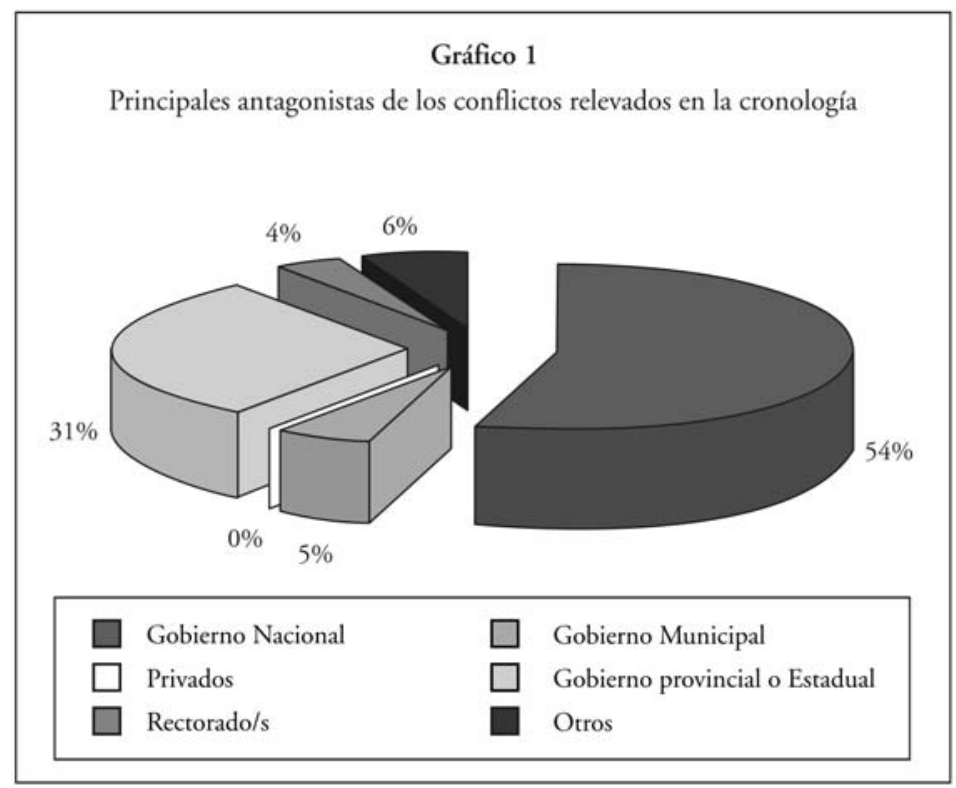

Educ. Soc., Campinas, vol. 25, n. 89, p. 1251-1274, Set./Dez. 2004 
Uno de los datos más impactantes de nuestra investigación es el referido a la duración de los conflictos registrados. Entre 1998 y 2003, la suma de las jornadas de conflicto educativo, en los 18 países estudiados, alcanzó 4.802 días. Considerando que el período analizado contempla 1.825 días, eso significa que, en 5 años, hubo en la región 2,6 jornadas de protesta educativa por día. La información precedente es meramente indicativa y poco nos dice acerca de la naturaleza y sentido de los conflictos desatados en ese período. Sin embargo, dicho dato resulta de vital importancia para comprender la magnitud de la conflictividad educativa en América Latina durante estos últimos años.

El Cuadro 1 presenta algunos datos relevantes, considerando la duración de los conflictos registrados en nuestra cronología:

- El país donde los conflictos educativos tuvieron una mayor duración temporal es la Argentina, con 1.491 jornadas de protesta. Eso significa que, durante parte del gobierno de Carlos $S$. Menem y en el conturbado período que siguió a la renuncia de Fernando de la Rua, descontando los días de receso escolar, hubo, en la Argentina, más de una jornada de protesta docente por día.

- Brasil es el segundo país en duración de la conflictividad educativa, con 1.118 días de acción sindical docente. En tercer lugar, con 978 días, se encuentra el México.

- Por otra parte, Bolivia, República Dominicana, Ecuador, Guatemala y Honduras tuvieron más de 100 días de luchas docentes directas; y Nicaragua y El Salvador son los países donde las jornadas de protesta fueron temporalmente más cortas, con $8 \mathrm{y}$ 13 días, respectivamente.

- México resultó el país con mayor número de días promedio por conflicto relevado (20,8 días). En Argentina y Ecuador, las acciones de protesta se prolongaron, en promedio, 14,3 días por conflicto registrado. En Brasil, 14,1 días; Guatemala, 12,2 días; Costa Rica, 9,4 días; Chile, 7,7 días; Bolivia, 7,3 días; Paraguay, 5,6 días; y Panamá, 5,5 días. En los países seleccionados, ninguna protesta tuvo una duración promedio menor a 3 días.

- El tiempo de duración promedio de las protestas docentes en América Latina ha sido, entre 1998 y 2003, de 11 días. 


\section{Cuadro 1}

\begin{tabular}{|c|c|c|c|c|c|}
\hline \multicolumn{6}{|c|}{ Duración de la protesta docente en 18 países de América Latina } \\
\hline \multirow{2}{*}{ País } & \multicolumn{3}{|c|}{ Número de protestas registradas } & \multicolumn{2}{|c|}{$\begin{array}{l}\text { Días de duración de la protesta } \\
\text { docente entre } 1998 \text { y } 2003\end{array}$} \\
\hline & $\begin{array}{c}\text { Total por } \\
\text { país }\end{array}$ & $\begin{array}{l}\text { Total por país } \\
\text { con registro de } \\
\text { duración } \\
\text { (A) }\end{array}$ & $\begin{array}{l}\text { Total por país sin } \\
\text { registro de } \\
\text { duración }\end{array}$ & $\begin{array}{l}\text { Total de días } \\
\text { (B) }\end{array}$ & $\begin{array}{c}\text { Promedio de días por } \\
\text { protesta relevada con } \\
\text { registro de duración } \\
\text { (B/A) }\end{array}$ \\
\hline Argentina & 146 & 104 & 42 & 1491 & 14,3 \\
\hline Bolivia & 51 & 26 & 25 & 192 & 7,3 \\
\hline Brasil & 117 & 79 & 38 & 1118 & 14,1 \\
\hline Chile & 11 & 4 & 7 & 31 & 7,7 \\
\hline Colombia & 31 & 20 & 11 & 85 & 4,2 \\
\hline Costa Rica & 11 & 5 & 6 & 47 & 9,4 \\
\hline R. Dominicana & 51 & 33 & 18 & 113 & 3,4 \\
\hline Ecuador & 22 & 13 & 9 & 186 & 14,3 \\
\hline Guatemala & 30 & 12 & 22 & 147 & 12,2 \\
\hline Honduras & 64 & 23 & 41 & 119 & 5,1 \\
\hline México & 150 & 47 & 103 & 978 & 20,8 \\
\hline Nicaragua & 9 & 2 & 7 & 8 & 4 \\
\hline Panamá & 26 & 7 & 19 & 39 & 5,5 \\
\hline Perú & 24 & 14 & 10 & 46 & 3,2 \\
\hline Paraguay & 27 & 11 & 16 & 62 & 5,6 \\
\hline El Salvador & 13 & 3 & 10 & 13 & 4,3 \\
\hline Uruguay & 23 & 20 & 3 & 71 & 3,5 \\
\hline Venezuela & 57 & 12 & 45 & 56 & 4,6 \\
\hline TOTAL & 863 & 435 & 428 & 4.802 & 11 \\
\hline
\end{tabular}

Obviamente, estos cálculos nada nos dicen respecto a la naturaleza de los conflictos que se llevaron a cabo ni, mucho menos, a su efectividad. Sería, por lo tanto, erróneo asociar la duración de los conflictos con la eficacia o ineficacia para obtener las demandas formuladas por parte de los actores que movilizaron las protestas docentes durante el período considerado. Sin embargo, en este caso también, los datos presentados nos alertan sobre la larga duración de la conflictividad social que acompañó a las reformas educativas implementadas en América Latina y nos alejan de 
la idílica imagen de diálogo y concertación que, siendo evidentemente inexacta, algunos sectores todavía hoy se esfuerzan en reafirmar.

Sin lugar a dudas, una reforma educativa democrática debe ser concertada y fundamentada en el diálogo y el consenso entre diversos actores sociales. No ha sido éste el caso de las reformas implementadas en los '80 y los '90. Siendo así, podemos reconocer que la alta conflictividad que las acompañó ha transformado la institucionalidad democrática que les dio marco en un elemento formal o meramente decorativo. Reformas educativas no democráticas en un Estado de derecho "democrático" no constituyen otra cosa que una evidencia más del profundo deterioro al que se han visto sometidas las instituciones públicas (históricamente débiles) en una región dominada por gobiernos conservadores y neoliberales.

Del total de acciones de protesta magisterial registradas, el 54\% han sido huelgas y paralizaciones (465 registros), el 57\% actos y marchas (496 registros) y el 27\%, otros tipos de manifestación (232 registros).

En cuanto a los tipos de reivindicaciones y demandas que motivan las acciones, el 79\% se debieron a cuestiones laborales (luchas por aumento salarial, sistema de jubilaciones y planes de carrera docente); el $28 \%$ estuvieron vinculadas a demandas de política educativa (aumento por presupuesto educativo, enfrentamientos contra los procesos de descentralización y transferencia, negociación sobre las leyes de educación, disputas alrededor de la implementación de sistemas de evaluación, de las reformas curriculares etc.); el $12 \%$ versaron sobre reivindicaciones de carácter políticas y sistémicas (exigencias de renuncias a autoridades gubernamentales, impugnación al modelo económico social vigente etc.); y el $6 \%$ sobre otros tipos de demanda no contempladas en las categorías anteriores (conflictos entre tendencias sindicales, demandas coyunturales etc.).

Las demandas por aumento salarial han estado en muchas ocasiones articuladas a reivindicaciones y cuestionamientos generales a la política educativa o sistémica. Como resulta evidente, las reivindicaciones de carácter laboral han sido las más frecuentes y abarcadoras (Cuadro 2).

Resulta particularmente interesante analizar la duración de las huelgas y paralizaciones en cada país relevado. Eso permite tener una noción más exacta de los días que, efectivamente, fueron paralizadas las actividades docentes en los establecimientos escolares de los países analizados. Los datos obtenidos evidencian que, con poquísimas excepciones, las huelgas y paralizaciones magisteriales siguen un modelo de protesta clásico y, en la generali- 


\section{Cuadro 2}

\begin{tabular}{|l|c|c|}
\hline \multicolumn{3}{|c|}{ Forma de protesta docente } \\
\hline & Total & $\%$ \\
\hline Huelgas y paralizaciones & 465 & 54 \\
\hline Actos y marchas & 496 & 57 \\
\hline Otras & 232 & 27 \\
\hline \multicolumn{2}{|c|}{ Tipos de reivindicación y demanda docente } \\
\hline \multicolumn{2}{|c|}{ Total } & $\%$ \\
\hline Laboral & 682 & 79 \\
\hline Política educativa & 244 & 28 \\
\hline Sistémica/Política & 100 & 12 \\
\hline Otras & 53 & 6 \\
\hline
\end{tabular}

dad de los casos, tienen un alto índice de adhesión. Sin lugar a dudas, un análisis más pormenorizado de cada caso concreto nos ofrecería una perspectiva detallada del impacto de estas formas de lucha en la cotidianeidad de los sistemas educativos. Como ya hemos indicado, nuestro relevamiento no permite ese tipo de abordaje. Sin embargo, un inventario como el que presentamos a seguir puede ofrecernos una visión de conjunto de la intensa conflictividad que ha marcado los procesos de reforma educativa en buena parte de los países de la región. Por otra parte, aunque las huelgas suponen la paralización de las actividades escolares, no son éstas las únicas formas de protesta que lo hacen. Teniendo en cuenta únicamente los días de paralización magisterial asociada a demandas laborales, de política educativa y/o sistémica, podemos presentar los siguientes datos:

- En los países seleccionados, el total de huelga suma 3.132 días, entre 1998 y 2003. Eso significa que, durante el período estudiado, hubo, en América Latina, 3 días de huelga por cada día del ciclo lectivo.

- La duración promedio de las huelgas magisteriales fue de 8,5 días.

- Los países donde las paralizaciones duran, en promedio, un tiempo mayor son: México (18,8 días), Guatemala (16,7 días), Brasil (14,5 días), Ecuador (14,3 días) y Costa Rica (9,4 días). 
- La alta intensidad de las huelgas, en algunos de los países estudiados, genera una gran concentración de días de protesta en unos pocos casos con relación al resto. De tal forma, la suma de los días de paralización en Argentina, Brasil, República Dominicana, Ecuador, Honduras y México concentra $80 \%$ del total de días de huelga en los países de la región (2.497 días).

- Nicaragua y El Salvador son los países con menos días de huelga magisterial (8 y 13 días, respectivamente). República Dominicana, Perú y Uruguay, los países donde las huelgas tienen, en promedio, un menor tiempo de duración (menos de 3,5 días). El caso dominicano es representativo entre los países con un alto número de paralizaciones de corta duración. Guatemala, de los países con un reducido número de huelgas, aunque de larga duración. Brasil, de los países con un alto número de huelgas, casi todas ellas de larga duración.

Vimos cómo la casi totalidad de los conflictos docentes son promovidos por actores sindicales, factor que podría explicar, en parte, la preponderancia de las reivindicaciones laborales en la estructuración de estas luchas. El reclamo por el pago de salarios atrasados, la reacción al pago por medio de bonos, o las demandas de recomposición salarial aparecen como los principales ejes estructuradores de las luchas magisteriales en América Latina. Sin embargo, cabe destacar que cuando esas reivindicaciones aparecen radicalizadas, dichas demandas suelen articularse en torno a consignas más amplias tales como la defensa de la educación pública y la resistencia a los procesos de privatización del sistema escolar impulsados por las administraciones neoliberales. Además de las reivindicaciones específicamente educativas, el sector docente ha sido un actor central en los procesos de movilización social impulsados por los sectores populares en los diversos países de la región.

\section{Consideraciones finales}

Más allá de sus peculiaridades y rasgos específicos, durante los últimos 20 años, los países de América Latina en su conjunto han sufrido cambios dramáticos en sus estructuras económicas y sociales, y han estado sometidos a profundos procesos de reforma, basados en principios de racionalización del gasto público y redefinición de las modalidades de 
intervención del Estado en materia económica, social y educativa. Un déficit fiscal crónico, el creciente endeudamiento externo, la pérdida de competitividad de las exportaciones regionales en el mercado internacional se presentaron como las causas más evidentes del "estancamiento regional", que "obligaba" a la implementación de un conjunto de medidas correctivas. El nuevo orden mundial globalizado y descarnadamente capitalista, las transformaciones en el modelo de acumulación y de circulación de capitales y la reconversión de los procesos productivos demandaban una serie de políticas dirigidas a modificar de raíz las pautas de gobierno estatal y el funcionamiento de las economías de los países de la región.

De esa forma, la apertura comercial y la desregulación de las economías nacionales, las políticas de ajuste estructural y de restricción del gasto social, los procesos de privatización y descentralización administrativa de los servicios, junto con una creciente ingerencia de los organismos internacionales de crédito en el diseño y financiamiento de las políticas estatales, resultaron rasgos característicos y comunes en la gran mayoría de los países latinoamericanos. Además, los procesos de reconversión y flexibilización laboral, y el consecuente deterioro de las condiciones de vida para la gran mayoría de la población, aparecieron como las marcas evidentes de sociedades cada vez más debilitadas, atravesadas por progresivos procesos de pauperización, fragmentación y exclusión social y por una profunda crisis institucional y política.

La implementación de esas políticas está estrechamente relacionada con el conjunto de medidas adoptadas en el campo educativo. En casi todos los países de la región, se llevaron adelante intensos programas de reforma de los sistemas escolares a la vez que se redefinían las incumbencias políticas, fiscales y administrativas del Estado en materia educativa. La desvinculación del Estado nacional de las responsabilidades de financiamiento y gestión de los establecimientos escolares, avalada por los principios de la "calidad, equidad y eficiencia", introdujo modificaciones radicales que interpelaron directamente a las instituciones educativas y a los distintos actores involucrados. Las modalidades históricas de gobierno y administración de los aparatos escolares, los marcos normativos que dirigían y organizaban el funcionamiento escolar, las condiciones y formas convencionales de regulación del trabajo docente, la organización misma de la enseñanza en las aulas, se vieron profundamente alteradas, al mismo tiempo que el malestar por el carácter inconsulto y vertical de las medidas de política se acrecentaba en la periferia de los sistemas. 
Los procesos de reforma coinciden con un aumento notable de la conflictividad educativa, convirtiéndola en un protagonista central de la creciente conflictividad social en la región. Cada vez con mayor intensidad y mediante distintas estrategias, los diversos actores del campo educativo, pero sobre todo los docentes sindicalizados, confrontan con los gobiernos a través de una permanente y cíclica lucha por instalar sus demandas y necesidades en la agenda de la política pública. El escenario educativo latinoamericano, pero también el campo político-social en su conjunto, se encuentran signados por la emergencia y la prolongación de acciones y manifestaciones de esta conflictividad, encarnadas y protagonizadas mayormente por los sindicatos docentes y sus antagonistas, los planteles políticos de gobierno y los elencos tecno-burocráticos de los aparatos estatales.

En este marco, las denominadas "políticas de concertación" aparecieron como uno de los ejes estratégicos centrales de los programas reformistas, con el fin de propiciar la construcción de consensos en torno a las orientaciones de política y medidas adoptadas, garantizando de esa forma la gobernabilidad y viabilidad de los cambios pretendidos. Diversos mecanismos de consulta, instancias de acuerdo y negociación, así como la delegación a las escuelas de las responsabilidades de gestión institucional y adaptación local y regional de lineamientos establecidos por los órganos centrales de gobierno, se presentaron como estrategias tendientes a generar nuevas estructuras y jerarquías de participación de los diversos actores de la comunidad educativa.

Sin embargo, resulta paradójico pensar en la efectividad de esas políticas y estrategias de concertación a la luz de la intensa y extendida conflictividad que acompañó los procesos de reforma educativa que tuvieron lugar en los países de la región. El análisis de los alcances y la dinámica de los procesos de confrontación educativa nos obligan a tener en cuenta la incidencia y el peso relativo de cada uno de los protagonistas involucrados en la definición de la agenda educativa. Cabe preguntarnos, entonces, en qué medida esas políticas y mecanismos implicaron instancias democráticas de deliberación, circulación de ideas y proyectos y participación real (es decir, con incidencia en la esfera de toma de decisiones) de los diversos actores educativos (particularmente los docentes) en las instancias de diseño y formulación de las políticas educativas. $\mathrm{O}$, por el contrario, en qué medida estas estrategias de construcción de consenso actuaron como auténticos mecanismos de legitimación del dis- 
curso y de la reforma neoliberal, pretendiendo imponer una determinada visión acerca de la educación y del trabajo docente.

De esa forma, la comprensión de las tendencias y dinámicas de la conflictividad educativa; la descripción del comportamiento y las posiciones relativas en la arena de disputas de los diversos actores comprometidos en los enfrentamientos; el análisis profundo de las modalidades y estrategias de lucha, disuasión, comunicación y alianzas empleadas por los contendientes; así como las tensiones y reformulaciones creativas de los diversos enfoques teóricos dirigidos a explicar y comprender en profundidad e históricamente los procesos de conflicto social, resultan necesarios incluso para dar cuenta de aspectos velados, oscuros, silenciados de las políticas educativas implementadas en América Latina en las últimas décadas.

Dicho de otra forma, la construcción de una interpretación crítica de los procesos de conflicto educativo y docente facilitaría la reflexión acerca de las políticas y reformas educativas implementadas en años recientes. Así, una teoría crítica del conflicto educativo y docente podría ofrecer elementos claves y puertas de entrada todavía inexploradas para el análisis de los sistemas escolares y sus tentativas de cambio y reestructuración.

\section{Recebido e aprovado em setembro de 2004.}

\section{Notas}

1. Para un seguimiento cronológico por país y diversos análisis sobre la conflictividad social en América Latina desde el año 2000, ver: ClACso, Observatorio Social de América Latina, números 1 al 13. Disponible en: <www.clacso.edu.ar>.

2. En un artículo que analiza las tendencias generales de la conflictividad social en América Latina, Seoane y Taddei (2001) señalan: "En primer lugar cabe señalar que el sector asalariado (público y privado) presenta el mayor porcentaje de acciones, situándose en un 30\% del total (...) Desagregados, ambos sectores presentan un índice de $18,57 \%$ para los asalariados del sector público y un $11.31 \%$ para los del sector privado. (...) De este conjunto se destacan para el presente período las acciones encaradas por maestros y profesores, que presentan el $6,22 \%$ de todos los registros".

3. Para acceder a una selección de noticias y reportes periodísticos, documentos y materiales que dan cuenta de diversos aspectos e impactos de las políticas educativas en los países de América Latina y el Caribe, ver los relevamientos realizados por el Observatorio Latinoamericano de Políticas Educativas (OLPED/LPP): <www.lpp-uerj.net/olped>

4. Para un interesante análisis crítico de los procesos de "globalización neoliberal", ver Slater (1996). Para un análisis de sus impactos en los países latinoamericanos, véanse los trabajos 
compilados en Gambina (2002) y Gentili (2001). Para un análisis crítico de la "tesis de los grandes efectos" de la globalización en el campo educativo, ver Brunner (2001).

5. Para consultar análisis críticos de los costos sociales de las políticas de ajuste estructural en América Latina, ver los trabajos publicados en Sader (2001).

6. En Gentili (1995) se pueden encontrar una serie de artículos que profundizan esta perspectiva. También, véase Feldfeber (2003).

7. Ver, por ejemplo: Birgin (1999); Tiramonti y Filmus (2001); y Torres (1999).

8. Para un análisis de los límites y potencialidades de esos cambios en la composición del salario y carrera docentes, ver: Morduchowicz (2002); también los trabajos editados en Murillo (2002).

9. Para un análisis de las tendencias mundiales de la descentralización educativa, ver Weiler (1996). Para consultar interesantes análisis críticos sobre el impacto de los procesos de descentralización educativa en América Latina y en Argentina, desde la perspectiva de los sindicatos docentes, ver Mango y Vázquez (2003).

10. Para un análisis de las modalidades top-down de gestión de las reformas educativas y sus consecuencias sobre la organización de los centros educativos, ver Bolívar (1996). Para un análisis de la reforma educativa y curricular en Argentina, ver Suárez (2003).

11. Véase, por ejemplo, Corrales (1999).

12. Bourdieu (1997, p. 84) hace referencia a los "campos" como "universos sociales relativamente autónomos". Es en esos campos de fuerzas donde se desarrollan los conflictos específicos entre los agentes involucrados. La educación, la burocracia, el intelectual, el religioso, el científico, el arte etc. son campos específicos; es decir, estructurados conforme a esos conflictos característicos en los que se enfrentan diversas visiones que luchan por imponerse. Para ampliar el concepto de "campo", véase Bourdieu (1997).

13. A partir de la realización de una Cronología de la acción sindical entre 1998 y 2003 en el marco del Estudio de los conflictos en los sistemas educativos de América Latina: agendas, actores, evolución, manejo y desenlaces, se ha buscado compilar los principales conflictos educativos, cuyo protagonista principal fueron las organizaciones sindicales del magisterio, entre 1998 y 2003. Pretendimos allí detectar las dimensiones que asumieron estas acciones reivindicativas, las formas como se expresaron, las demandas que las motivaron y los actores que en ellas estuvieron involucrados. Este abordaje, aunque limitado en su capacidad para determinar dinámicas específicas y ciertas características peculiares a cada caso nacional, nos permitió, sin embargo, ofrecer una visión de conjunto que puede contribuir a la reflexión crítica y rigurosa acerca de una de las cuestiones más polémicas de la investigación sobre políticas educativas en los países de la región.

14. Argentina, Bolivia, Brasil, Chile, Colombia, Costa Rica, Ecuador, El Salvador, Guatemala, Honduras, México, Nicaragua, Panamá, Paraguay, Perú, República Dominicana, Uruguay y Venezuela.

15. Hay, naturalmente, algunas significativas excepciones a esta observación. El proyecto "Sindicalismo Docente y Reforma Educativa" del PREAL es una de ellas. También lo es buena parte de la bibliografía cuyo acceso está disponible, de manera general, en la página web del Observatorio Latinoamericano de Políticas Educativas (OLPED/LPP): <www.lpp-uerj.net/olped/ conflictos>.

16. Las tareas de relevamientos de conflictos educativos continúan, en una segunda etapa de esta investigación, considerando el período 2004-2005. Esta segunda etapa cuenta con el apoyo del Foro Latinoamericano de Políticas Educativas (FLAPE). 


\section{Referências bibliograficas}

BIRGIN, A. La regulación del trabajo de enseñar. Buenos Aires: Troquel, 1999.

BOLÍVAR, A. El lugar del centro escolar en la política curricular actual: más allá de la reestructuración y de la descentralización. In: PEREYRA, M. et al. (Comp.). Globalización y descentralización de los sistemas educativos: fundamentos para un nuevo programa de la educación comparada. Barcelona: Pomares-Corredor, 1996.

BOURDIEU, P. Razones prácticas: sobre la teoría de la acción. Barcelona: Anagrama, 1997.

BRUNNER, J.J. Globalización y el futuro de la educación: tendencias, desafíos, estrategias. In: UnESCO. Análisis de prospectivas de la educación en América Latina y el Caribe. Santiago de Chile: UNESCO, 2001.

CONSEJO LATINOAMERICANO DE CIENCIAS SOCIALES (CLACSO). Observatorio Social de América Latina, n.1-13, 2000-2004. Disponivel em: <http://www.clacso.edu.ar>. Acesso em: 2004.

CORRALES, J. Aspectos politicos en la implementación de las reformas educativas. Santiago de Chile: PREAL, 1999. (Documento de trabajo, n. 14).

GAMBINA, J. (Comp.). La globalización económico-financiera: su impacto en América Latina. Buenos Aires: CLACSO, 2002.

GENTILI, P. (Org.). Pedagogia da exclusão: crítica ao neoliberalismo em educação. Petrópolis: Vozes, 1995.

GENTILI, P. (Comp.). Globalização excludente: desigualdade, exclusão e democracia na nova ordem mundial. Petrópolis: Vozes, 2001.

GENTILI, P.; SUÁREZ, D. (Org.). Reforma educacional e luta democrática: um debate sobre a ação sindical docente na América Latina. São Paulo: Cortez, 2004.

FELDFEBER, M. (Comp.). Los sentidos de lo público: reflexiones desde el campo educativo. Buenos Aires: NOvEDUC, 2003.

MANGO, M.; VÁZQUEZ, S. (Comp.). Descentralización y municipalización: el debate del espacio público en la escuela. Buenos Aires: CTERA, 2003. 
MORDUCHOWICZ, A. Carreras, incentivos y estructuras salariales docentes. Buenos Aires: PreAl-Flacso, 2002. (Documento de trabajo, n. 23). MURILLO, M.V. (Ed.). Carreras magisteriales, desempeño educativo y sindicatos de maestros en América Latina. Buenos Aires: FLACSO, 2002.

PEREYRA, M. et al. (Comp.). Globalización y descentralización de los sistemas educativos: fundamentos para un nuevo programa de la educación comparada. Barcelona: Pomares-Corredor, 1996.

SADER, E. (Comp.). El ajuste estructural en América Latina: costos sociales y alternativas. Buenos Aires: CLACSO, 2001.

SEOANE, J.; TADDEI, E. Protesta social, ajuste y democracia: la encrucijada latinoamericana. Observatorio Social de América Latina, Buenos Aires, v.2, n. 4, jun. 2001.

SLATER, D. La geopolítica del proceso globalizador y el poder territorial de las relaciones Norte-Sur: imaginaciones desafiantes de lo global. In: Pereyra, M. et al. (Comp.). Globalización y descentralización de los sistemas educativos: fundamentos para un nuevo programa de la educación comparada. Barcelona: Pomares-Corredor, 1996.

SUÁREZ, D. Los efectos pedagógicos de la reforma educativa de los '90 en Argentina: reconfiguración del currículum, descalificación docente y control tecnocrático. Revista Novedades Educativas, Buenos Aires, v. 15, n. 155 , dic. 2003.

TIRAMONTI, G. Sindicalismo docente y reforma educativa en la América latina de los '90. Buenos Aires: PREAL, 2001. (Documento de trabajo, n. 19)

TIRAMONTI, G.; FILMUS, D. (Coord.). Sindicalismo docente e reforma en América Latina. Buenos Aires: FlaCso; Temas Grupo, 2001.

TORRES, C.A. El rol de los sindicatos docentes, el Estado y la sociedad en la reforma educativa. Boletin n. 2 del Proyecto "Sindicalismo docente y reforma educativa en América Latina”. Buenos Aires: FLACSO-PREAL, 1999.

WEILER, H. Enfoques comparados en descentralización educativa. In: Pereyra, M. et al. (Comp.). Globalización y descentralización de los sistemas educativos: fundamentos para un nuevo programa de la educación comparada. Barcelona: Pomares-Corredor, 1996. 